\title{
Islet constitutive nitric oxide synthase and glucose regulation of insulin release in mice
}

\author{
B Åkesson, R Henningsson, A Salehi and I Lundquist \\ Department of Pharmacology, University of Lund, Lund, Sweden \\ (Requests for offprints should be addressed to I Lundquist, Department of Pharmacology, Sölvegatan 10, S-223 62 Lund, Sweden; \\ Email: Ingmar.Lundquist@farm.lu.se)
}

\begin{abstract}
We have studied, by a combined in vitro and in vivo approach, the relation between the inhibitory action of $\mathrm{N}^{\mathrm{G}}$-nitro-L-arginine methyl ester (L-NAME), a selective inhibitor of nitric oxide synthase (NOS), on the activity of islet constitutive NOS (cNOS) and glucose regulation of islet hormone release in mice. The cNOS activity in islets incubated in vitro at $20 \mathrm{mM}$ glucose was not appreciably affected by 0.05 or $0.5 \mathrm{mM}$ L-NAME, but was greatly suppressed (-60\%) by $5 \mathrm{mM}$ L-NAME. Similarly, glucosestimulated insulin release was unaffected by the lower concentrations of L-NAME but greatly enhanced in the presence of $5 \mathrm{mM}$ of the NOS inhibitor. In incubated islets inhibition of cNOS activity resulted in a modestly enhanced insulin release in the absence of glucose, did not display any effect at physiological or subphysiological glucose concentrations, but resulted in a markedly potentiated insulin release at hyperglycaemic glucose concentrations. In the absence of glucose, glucagon secretion was suppressed by L-NAME. The dynamics of glucoseinduced insulin release and ${ }^{45} \mathrm{Ca}^{2+}$ efflux from perifused
\end{abstract}

islets revealed that L-NAME caused an immediate potentiation of insulin release, and a slight increase in ${ }^{45} \mathrm{Ca}^{2+}$ efflux. In islets depolarized with $30 \mathrm{mM} \mathrm{K}^{+}$in the presence of the $\mathrm{K}^{+}{ }_{\text {ATP }}$ channel opener, diazoxide, L-NAME still greatly potentiated glucose-induced insulin release. Finally, an i.v. injection of glucose to mice pretreated with L-NAME was followed by a markedly potentiated insulin response, and an improved glucose tolerance. In accordance, islets isolated directly ex vivo after L-NAME injection displayed a markedly reduced cNOS activity. In conclusion, we have shown here, for the first time, that biochemically verified suppression of islet cNOS activity, induced by the NOS inhibitor L-NAME, is accompanied by a marked potentiation of glucosestimulated insulin release both in vitro and in vivo. The major action of NO to inhibit glucose-induced insulin release is probably not primarily linked to changes in $\mathrm{Ca}^{2+}$ fluxes and is exerted mainly independently of membrane depolarization events.

Journal of Endocrinology (1999) 163, 39-48

\section{Introduction}

It is now well documented that nitric oxide (NO) is a novel type of messenger molecule, which is involved in the signal transduction of many different physiological functions (Kerwin \& Heller 1994, Knowles \& Moncada 1994). NO is formed from the metabolism of L-arginine through the action of NO synthase (NOS). By means of a newly developed biochemical microtechnique we recently proved the existence of a constitutive NOS (cNOS) activity in isolated mouse islets (Salehi et al. 1996) thus verifying previous histochemical and immunocytochemical observations in rodent islets (Panagiotidis et al. 1992a, Schmidt et al. 1992, Corbett et al. 1993, Panagiotidis et al. 1994). Functional data from our laboratory (Panagiotidis et al. 1992a, 1994, 1995, Åkesson \& Lundquist 1996, Salehi et al. 1996, Ả kesson \& Lundquist 1998, Henningsson et al. 1999) have unambiguously suggested that NO negatively modulates insulin secretory processes induced by L-arginine, glucose, sulphonylurea and cholinergic stimulation, whereas $\mathrm{NO}$, in contrast, is stimulatory to glucagon release. Similar results regarding insulin secretion were reported from other laboratories (Cunningham et al. 1994, Gross et al. 1995, Antoine et al. 1996, Sjöholm 1996), whereas no effects (Jones et al. 1992) or even a stimulatory action by $\mathrm{NO}$ on insulin release (Laychock et al. 1991, Schmidt et al. 1992, Laffranchi et al. 1995, Willmott et al. 1995, Spinas et al. 1998) have been observed. Hence, there is presently no consensus as to whether NO in fact inhibits, stimulates, or has no appreciable effect on the insulin secretory mechanisms. This might be due to different experimental conditions such as incubation of islets in high or low glucose, the use of different NOS inhibitors or different types of extracellular and intracellular NO donors, as well as the use of intact islets versus $\beta$-cell lines. However, much of this confusion certainly emanates from the fact that until now, as far as the authors are aware, there are no direct biochemical 
measurements of islet cNOS activity in intact incubated islets correlating to its putative effects on insulin release.

The purpose of the present investigation was to measure directly, both in vitro and in vivo, the islet cNOS activity in the absence and presence of a selective inhibitor of NOS, the arginine analogue $\mathrm{N}^{\mathrm{G}}$-nitro-L-arginine methyl ester (L-NAME) (Moncada et al. 1991, Kerwin \& Heller 1994, Southan \& Szabó 1996) in relation to the effects of cNOS-derived NO on glucose regulation of insulin and glucagon release. It will be shown here, for the first time, that the potentiating effect of L-NAME on glucoseinduced insulin release is correlated to its ability to inhibit islet $\mathrm{cNOS}$ activity both in vitro and in vivo.

\section{Materials and Methods}

\section{Animals}

Female mice of the NMRI strain (B \& K, Sollentuna, Sweden), weighing 25-30 g, were used throughout the experiments. A standard pellet diet $(\mathrm{B} \& \mathrm{~K})$ and tap water were available ad libitum. The animal experiments were approved by the local animal welfare committee (Lund, Sweden).

\section{Drugs and chemicals}

Collagenase (CLS-4) was purchased from Worthington Biochemical Corporation (Freehold, NJ, USA). The NO synthase inhibitor $\mathrm{N}^{\mathrm{G}}$-nitro-L-arginine methyl ester (LNAME) as well as hydroxylamine and diazoxide were obtained from Sigma Chemical Co. (St Louis, MO, USA). ${ }^{45} \mathrm{Ca}^{2+}$ was from the Radiochemical Centre Ltd (Amersham, Bucks, UK). Bovine serum albumin was from ICN Biomedicals Ltd (High Wycombe, Bucks, UK). All other drugs and chemicals were from BDH Ltd (Poole, Dorset, UK) or Merck AG (Darmstadt, Germany). The radioimmunoassay kits for insulin and glucagon determinations were obtained from NOVO (Bagsvœrd, Denmark), Diagnostika (Falkenberg, Sweden) and Eurodiagnostica Ltd (Malmö, Sweden). The antiserum used in the glucagon assay is highly selective against glucagon (Eurodiagnostica Ltd).

\section{Experimental protocol}

Hormone secretion Preparation of isolated pancreatic islets from the mouse was performed by retrograde injection of a collagenase solution via the bile-pancreatic duct (Gotoh et al. 1985). In batch incubation experiments, freshly isolated islets were preincubated for $30 \mathrm{~min}$ at $37^{\circ} \mathrm{C}$ in Krebs-Ringer bicarbonate (KRB) buffer, $\mathrm{pH} 7 \cdot 4$, supplemented with $10 \mathrm{mM}$ HEPES and $0 \cdot 1 \%$ bovine serum albumin (Panagiotidis et al. 1992a, Akesson et al. 1996). Each incubation vial was gassed with $95 \% \mathrm{O}_{2}$ and
$5 \% \mathrm{CO}_{2}$ to obtain constant $\mathrm{pH}$ and oxygenation. After preincubation the buffer was changed to a medium supplemented with the different test agents and the islets (10 islets per $1.0 \mathrm{ml}$ medium in each incubation vial) were incubated for $60 \mathrm{~min}$. All incubations were performed at $37^{\circ} \mathrm{C}$ in an incubation box ( 30 cycles per min). The test and control data were always obtained within each experiment. Each experiment comprised 24-30 incubation vials containing islets obtained from one single pool prepared from 2-3 mice. Immediately after incubation aliquots of the medium were removed and frozen for subsequent radioimmunoassay of insulin and glucagon (Heding 1966, Ahrén \& Lundquist 1982, Panagiotidis et al. 1992b). The inter- and intra-assay coefficients of variance were 6.0 and $3.5 \%$ for insulin and $12 \cdot 9$ and $7 \cdot 3 \%$ for glucagon.

In the perifusion experiments, islets $(300-375)$ were loaded with $50 \mu \mathrm{l}{ }^{45} \mathrm{CaCl}_{2}(50-100 \mu \mathrm{Ci})$ (Salehi et al. 1998a) which were added from a stock solution with a specific activity of $10-40 \mathrm{mCi} / \mathrm{mg} \mathrm{Ca}{ }^{2+}$. The islets were then washed three times with nonradioactive medium, divided into 2-3 groups with 100-125 islets per group and transferred to perifusion columns. The islets were thereby sandwiched between two layers of gel (Bio-gel P-4, 200-400 mesh) (Bio-Rad Laboratory, Richmond, CA, USA) and perifused at a rate of $0.1 \mathrm{ml} / \mathrm{min}$ with the KRB buffer supplemented with $7 \mathrm{mM}$ glucose. The perifusion medium was gassed with $95 \% \mathrm{O}_{2}$ and $5 \% \mathrm{CO}_{2}$ and the test substances were introduced according to the protocols. The radioactivity lost by the islets was measured in effluent fractions collected every $2 \mathrm{~min}(50 \mu \mathrm{l}$ of the sample was added to $5 \mathrm{ml}$ scintillation fluid) and counted in a scintillation counter (Packard Instrument Inc., Downers Groove, IL, USA). The fractional efflux rate was calculated for each period (radioactivity lost by islets during the time interval/ radioactivity present in the islets during the same time interval) and the mean value calculated at 38 and $40 \mathrm{~min}$ was then normalized to 100\% (Salehi et al. 1998a). Insulin was determined with a radioimmunoassay (Heding 1966).

Assay of islet cNOS Preparation of isolated pancreatic islets from the mouse was performed by retrograde injection of a collagenase solution via the bile-pancreatic duct (Gotoh et al. 1985). Islets were then isolated and handpicked under a stereomicroscope at room temperature. The freshly isolated islets were then preincubated and incubated as described above for batch incubation experiments. Each incubation vial contained 200 islets in $2 \mathrm{ml}$ buffer. After incubation for $60 \mathrm{~min}$ the islets were thoroughly washed and collected in ice-cold buffer (200 islets in $840 \mu \mathrm{l}$ buffer) containing $20 \mathrm{mM} \mathrm{N}$-2-hydroxyethylpiperazine-N'-2-ethanesulphonic acid (HEPES), $0.5 \mathrm{mM}$ EDTA, and $1 \mathrm{mM} \mathrm{D,L-dithiothreitol,} \mathrm{pH} 7 \cdot 2$, and immediately frozen at $-20^{\circ} \mathrm{C}$. On the day of assay, the islets were sonicated on ice, and the buffer solution containing the islet homogenate was supplemented so as to contain $0.45 \mathrm{mM} \mathrm{CaCl}_{2}, 2 \mathrm{mM} \mathrm{NADPH}, 25 \mathrm{U}$ 
calmodulin and $0.2 \mathrm{mM}$ L-arginine in a total volume of $1 \mathrm{ml}$. The buffer composition is essentially the same as previously described for the assay of NOS in brain tissue using radiolabelled L-arginine (Bredt \& Snyder 1989). The homogenate was then incubated at $37^{\circ} \mathrm{C}$ under constant air bubbling, $1.0 \mathrm{ml} / \mathrm{min}$, for $3 \mathrm{~h}$. It was ascertained that under these conditions the reaction velocity was linear for at least $6 \mathrm{~h}$. Aliquots of the incubated homogenate $(200 \mu \mathrm{l})$ were then passed through a $1 \mathrm{ml}$ Amprep CBA cationexchange column for high-performance liquid chromatography (HPLC) analysis. The amount of L-citrulline formed was then measured in a Hitachi F 1000 fluorescence spectrophotometer (Merck) as previously described (Salehi et al. 1996). NO and L-citrulline are produced in equimolar concentrations. The methodology has been described in detail earlier (Carlberg 1994, Salehi et al. 1996), the only difference being that the incubation was now performed at $37^{\circ} \mathrm{C}$ instead of at room temperature. Protein was determined according to Bradford (1978) on samples from the original homogenate.

In vivo studies D-Glucose and L-NAME were dissolved in $0.9 \% \mathrm{NaCl}$. The agents were injected i.v. (volume load $5 \mu \mathrm{l} / \mathrm{g}$ mouse). Pretreatment with L-NAME or saline $(0.9 \% \mathrm{NaCl})$ was performed with an i.v. injection $15 \mathrm{~s}$ before the injection of $\mathrm{D}$-glucose. Basal controls received saline. Blood sampling was performed as described previously (Rerup \& Lundquist 1966). The concentrations of insulin and glucagon in plasma were determined by radioimmunoassay (Heding 1966, Ahrén \& Lundquist 1982, Panagiotidis et al. 1992b). Plasma glucose concentrations were determined enzymatically (Bruss \& Black 1978).

\section{Statistics}

Probability levels of random differences were determined by Student's unpaired t-test or analysis of variance followed by Tukey-Kramer's multiple comparisons test where applicable.

\section{Results}

Influence of different concentrations of L-NAME on islet cNOS activity

Isolated, intact islets were incubated for $60 \mathrm{~min}$ at $20 \mathrm{mM}$ glucose in the absence and presence of different concentrations of the NOS inhibitor L-NAME. The islets were thereafter thoroughly washed, homogenized and analysed for cNOS activity. Figure 1 (upper panel) shows that 50 and $500 \mu \mathrm{M}$ L-NAME had no appreciable effect on islet cNOS activity. A concentration of $5 \mathrm{mM}$ L-NAME, however, markedly suppressed islet cNOS activity by approximately $60 \%$. Glucose-induced insulin release (lower panel) was unaffected by 50 and $500 \mu \mathrm{M}$ L-NAME
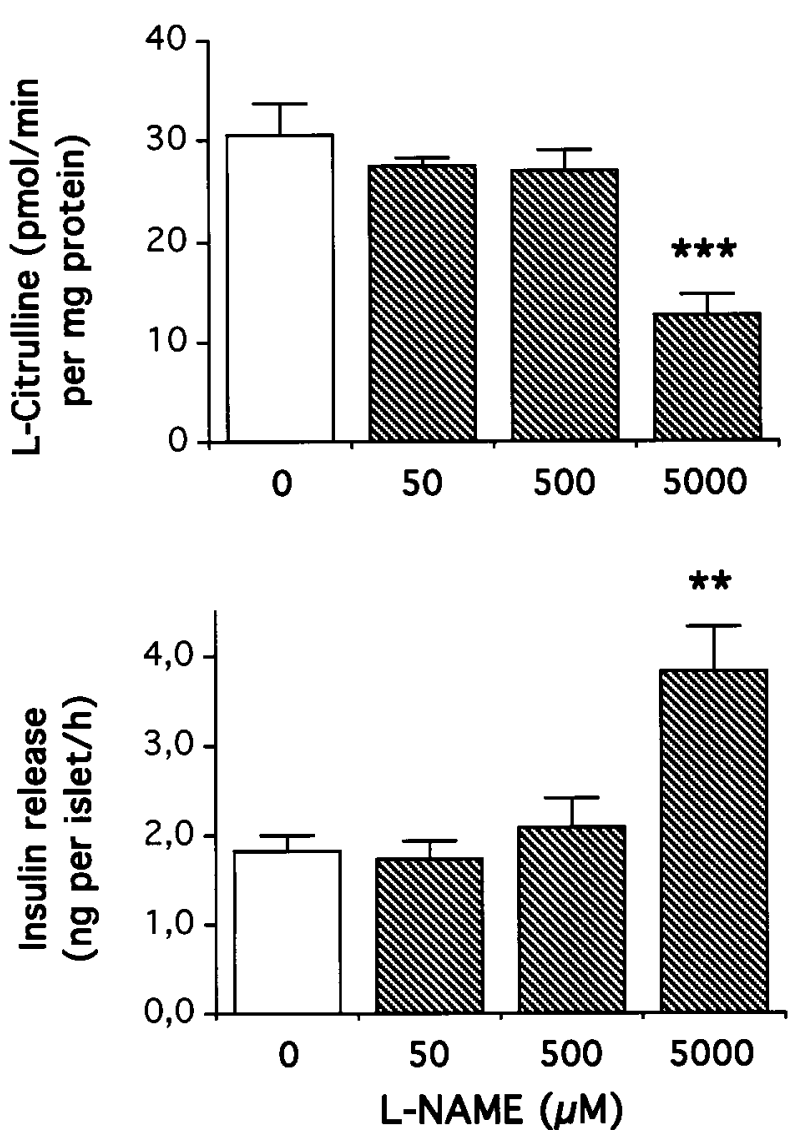

Figure 1 Effect of different concentrations of L-NAME on islet cNOS activity and glucose-induced insulin release. cNOS activity in intact islets (upper panel) and insulin release (lower panel) were measured after incubation at $20 \mathrm{mM}$ glucose in the absence and presence of different concentrations of the NOS inhibitor,

L-NAME. NO production was measured as L-citrulline formation ( $\mathrm{pmol} / \mathrm{min} / \mathrm{mg}$ protein). Groups of 200 islets per $1.5 \mathrm{ml}$ medium, taken from a pool of 800 islets isolated from 3-4 mice in each experiment, were incubated for $60 \mathrm{~min}$. Values are means \pm S.E.M. for $4-5$ observations in each category. ${ }^{* *} P<0 \cdot 01,{ }^{* * *} P<0 \cdot 001$ compared with control (open columns).

but was greatly enhanced in the presence of $5 \mathrm{mM}$ of the NOS inhibitor.

Effect of NOS inhibition by L-NAME on insulin and glucagon release in the presence of different concentrations of glucose

In a large series of experiments we monitored insulin and glucagon release from isolated islets at different concentrations of glucose in the absence or presence of $5 \mathrm{mM}$ L-NAME. Figure 2 illustrates that inhibition of cNOS activity by L-NAME modestly enhanced insulin release in the absence of glucose and markedly enhanced it at glucose concentrations stimulating insulin release i.e. at 12, 16.7, 22 and $30 \mathrm{mM}$ glucose. In contrast no effect 

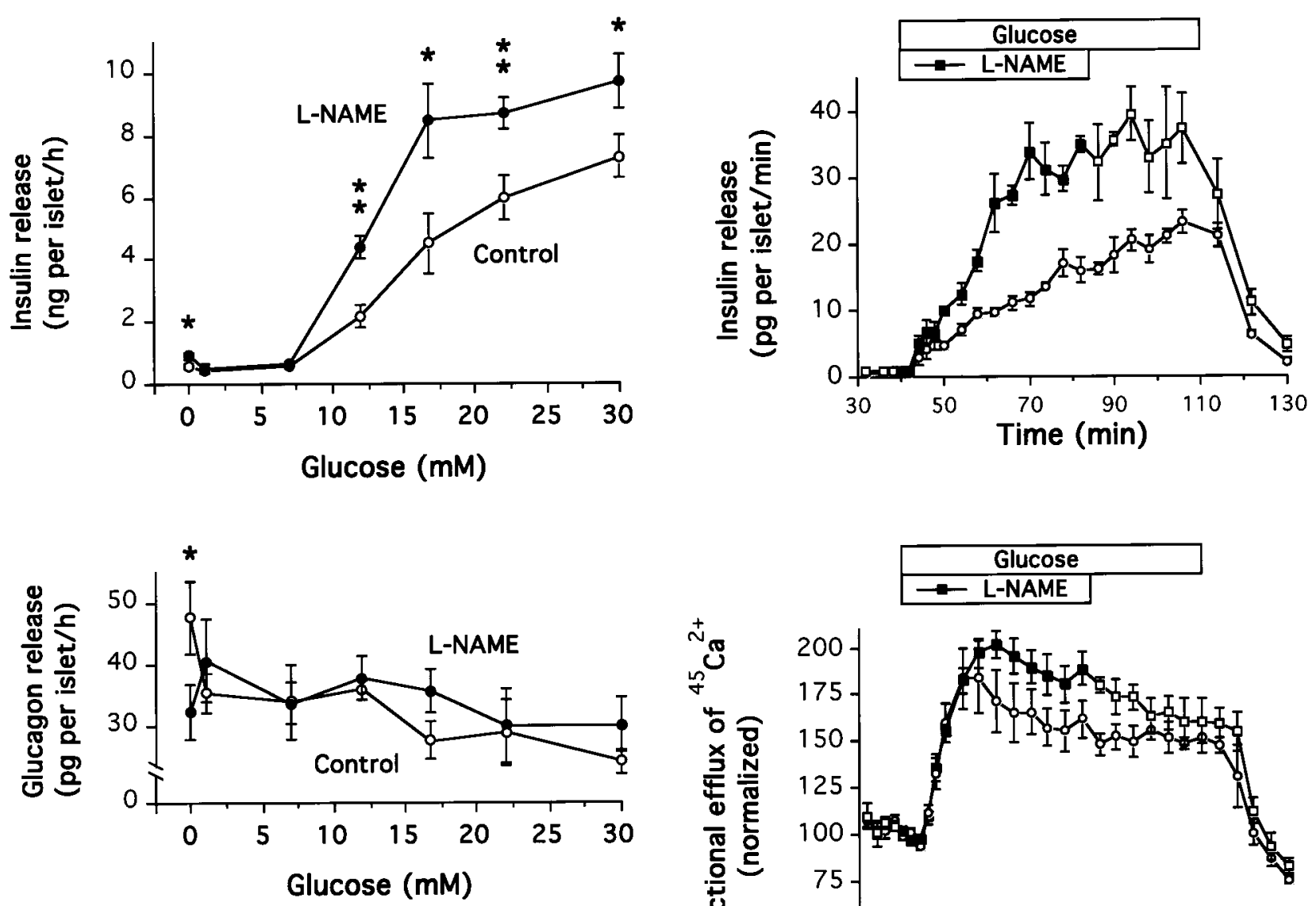

Figure 2 Dose-response curves for the effects of different concentrations of glucose on islet hormone release in the absence and presence of L-NAME: the effect of the NOS inhibitor L-NAME on insulin (upper panel) and glucagon (lower panel) release from isolated islets at different concentrations of glucose. Islets (250-300) from 2-3 mice in each experiment were pooled. Groups of 10 islets per $1 \mathrm{ml}$ medium were then incubated for $60 \mathrm{~min}$ in the absence $(\bigcirc)$ or presence $(\bullet)$ of $5 \mathrm{mM} \mathrm{L-NAME}$. Controls were always included at each point, although not all points were tested in each experiment. Values are means \pm S.E.M. for $5-8$ batches of islets at each point. ${ }^{*} P<0 \cdot 05,{ }^{* *} P<0 \cdot 01$ compared with control.

at all was observed at low, basal non-stimulatory glucose concentrations i.e. at 1 and $7 \mathrm{mM}$. Furthermore, the dose-response curve for glucose-induced insulin release was shifted to the left by the NOS inhibitor. Figure 2 (lower panel) also shows the effect of L-NAME on glucagon release. In the absence of glucose the NOS inhibitor significantly suppressed glucagon release, whereas no appreciable effect was observed at any of the glucose concentrations tested.

Influence of NOS inhibition by L-NAME on the dynamics of glucose-induced insulin release and ${ }^{45} \mathrm{Ca}^{2+}$ efflux pattern from perifused islets

The next series of experiments was designed to study the time-dependence of the NOS-inhibitory effect exerted by

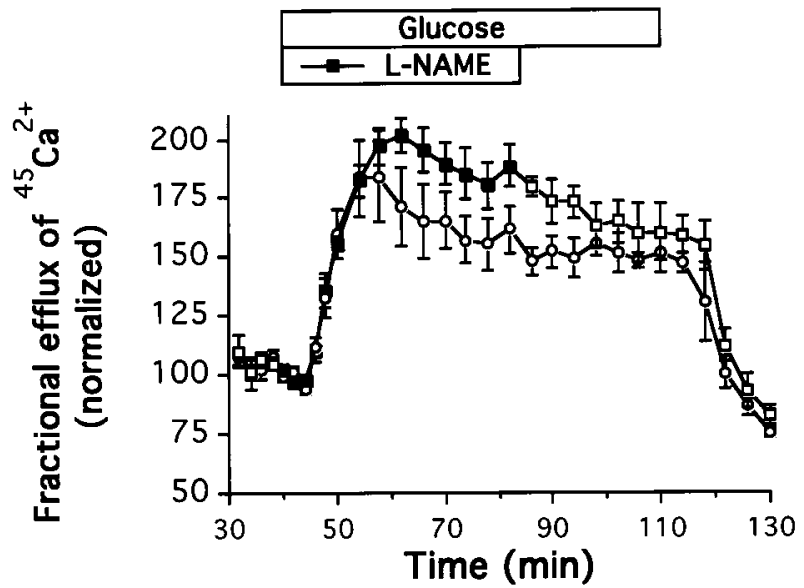

Figure 3 Dynamics of glucose-induced insulin release and ${ }^{45} \mathrm{Ca}^{2+}$ efflux from perifused islets in the absence and presence of L-NAME: the effect of $20 \mathrm{mM}$ glucose on insulin release (upper panel) and ${ }^{45} \mathrm{Ca}^{2+}$ efflux (lower panel) in the absence $(\bigcirc)$ or presence $(\mathbf{\square})$ of the NOS inhibitor, L-NAME $(5 \mathrm{mM})$. Glucose or glucose+L-NAME were introduced at $40 \mathrm{~min}$ as indicated. L-NAME was then withdrawn at 85 min and glucose alone ( $\square$ ) was present until $110 \mathrm{~min}$ as indicated. The fractional efflux rate was calculated and normalized as described in Materials and Methods. Values are means \pm S.E.M. from 3-4 perifusion columns in each group obtained from 3 independent experiments.

L-NAME on glucose-stimulated insulin release in a system of perifused islets. In addition we loaded these islets with ${ }^{45} \mathrm{Ca}^{2+}$ and monitored the ${ }^{45} \mathrm{Ca}^{2+}$ movements to elucidate any influence of L-NAME on the $\mathrm{Ca}^{2+}$ efflux pattern. Figure 3 (upper panel) shows, as judged from the pattern of insulin release, that the NOS-inhibitory effect of L-NAME was very rapid since insulin release stimulated by glucose + L-NAME was already greater than the release stimulated by glucose alone a few minutes after the introduction of the agents into the perifusion system. The potentiating effect by L-NAME on glucose-induced insulin release then became more and more pronounced 
with increased glucose infusion time. In contrast, L-NAME displayed little effects on the ${ }^{45} \mathrm{Ca}^{2+}$ efflux pattern (Fig. 3, lower panel). No influence at all was observed during the first $10 \mathrm{~min}$ of infusion after which a slight stimulatory effect by L-NAME was evident. In order to study the effects of L-NAME withdrawal the infusion of the NOS inhibitor was stopped at $85 \mathrm{~min}$ and the perifusion continued with glucose alone. As can be seen from Fig. 3 the enhanced insulin release from these islets was unaffected by L-NAME withdrawal and persisted at a high level until glucose infusion was stopped. However, the ${ }^{45} \mathrm{Ca}^{2+}$ efflux curve in the glucose+ L-NAME group tended to decrease after L-NAME withdrawal.

Effect of L-NAME at $20 \mathrm{mM}$ glucose on hormone release from islets depolarized by $30 \mathrm{mM} \mathrm{K}$ and in the presence of the $K^{+}$ATP channel opener, diazoxide

Since recent data (Krippeit-Drews et al. 1996) suggested that L-NAME at very high concentrations $(>5 \mathrm{mM})$ has the ability to induce closure of the $\mathrm{K}^{+}$ATP channels, we performed an experiment to study the pattern of islet hormone release in the presence of $5 \mathrm{mM}$ L-NAME, 20 $\mathrm{mM}$ glucose, $30 \mathrm{mM} \mathrm{K}^{+}$and $250 \mu \mathrm{M}$ diazoxide, thus circumventing putative effects of L-NAME on membrane depolarization events in the $\beta$-cell. For comparison nondepolarized islets were included (Fig. 4, left hand columns). Figure 4 shows, largely in accordance with the cNOS inhibitory action of L-NAME in normal islets (Fig. 4, left hand columns and Fig. 1, lower panel), that the L-NAME-induced potentiation of glucose-stimulated insulin release in depolarized, diazoxide-treated islets was markedly evident at a concentration of $5 \mathrm{mM}$ NOS inhibitor. In contrast, as expected, glucagon release (Fig. 4, lower panel) was unaffected by L-NAME.

In vivo dynamics of insulin and glucagon release as well as plasma glucose levels following stimulation by glucose after pretreatment with L-NAME or saline

Groups of mice were pretreated with a rapid i.v. injection of L-NAME $(1.2 \mathrm{mmol} / \mathrm{kg})$. After $15 \mathrm{~s}$ the animals were injected i.v. with glucose $(3.3 \mathrm{mmol} / \mathrm{kg})$ and the dynamics of the insulin, glucagon and glucose responses were monitored and compared with the responses in an appropriate control group of animals pretreated with 0.9\% $\mathrm{NaCl}$. Figure 5A shows that the glucose-stimulated insulin response was markedly enhanced, and the glucagon levels suppressed after pretreatment with the NOS inhibitor, when compared with the control group. The increased insulin response and the suppression of the glucagon levels were reflected in a markedly improved glucose tolerance in animals pretreated with L-NAME (Fig. 5A).
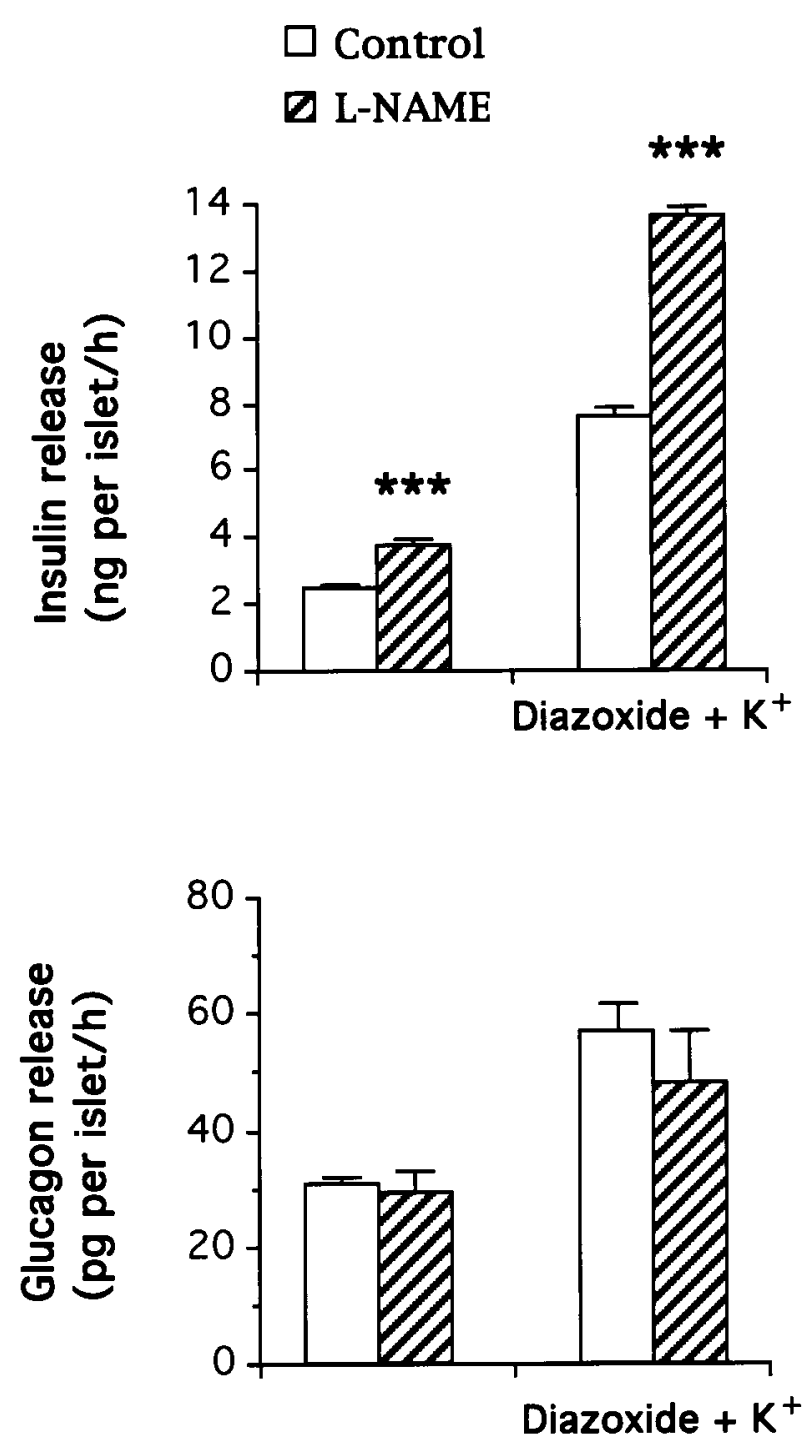

Figure 4 Influence of L-NAME on the effects of glucose on islet hormone release in normal (the two columns on the left) and depolarized (the two columns on the right) islets: the effect of the NOS inhibitor, L-NAME, on insulin and glucagon release from isolated islets at $20 \mathrm{mM}$ glucose in the absence or presence of $30 \mathrm{mM} \mathrm{K}^{+}$and $250 \mu \mathrm{M}$ diazoxide. Groups of 10 islets per $1 \mathrm{ml}$ medium were incubated for $60 \mathrm{~min}$ in the absence (open columns) or presence (hatched columns) of $5 \mathrm{mM} \mathrm{L-NAME.}$ Values are means \pm S.E.M. for $7-9$ batches of islets in each category. ${ }^{* * *} P<0 \cdot 001$ compared with respective control.

Effect of in vivo injection of L-NAME on islet cNOS activity

Groups of mice were injected i.v. with either L-NAME $(1.2 \mathrm{mmol} / \mathrm{kg})$ or $0.9 \% \mathrm{NaCl}$. To study the acute effect of L-NAME on islet cNOS activity i.e. at the peak of insulin release at 2 min (shown in Fig. 5), the mice were killed by cervical dislocation $2 \mathrm{~min}$ after the injection of L-NAME 
A
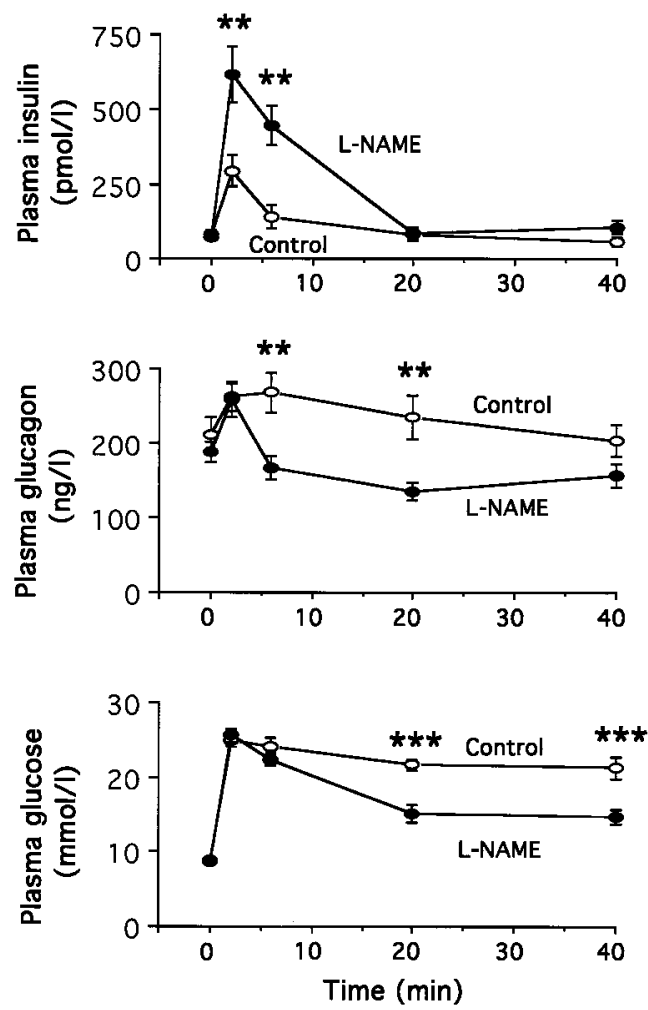

B

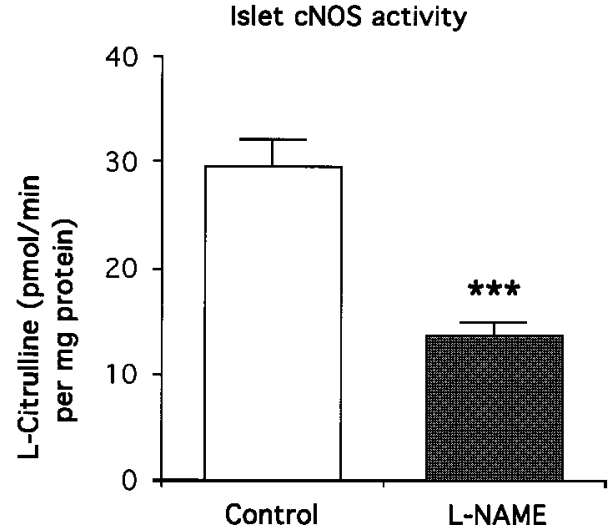

Figure 5 (A) In vivo action of L-NAME on plasma levels of insulin, glucagon and glucose after an i.v. glucose load: the effect of i.v. pretreatment with the NOS inhibitor, L-NAME $(1 \cdot 2 \mathrm{mmol} / \mathrm{kg})($ or saline $(\bigcirc)$ on the plasma concentrations of insulin, glucagon and glucose after an i.v. injection of an approximately half-maximal dose of glucose $(3.3 \mathrm{mmol} / \mathrm{kg})$. L-NAME or saline was given $15 \mathrm{~s}$ before glucose. Values, obtained from two independent experiments, are means \pm S.E.M. from 12-18 animals in each group. ${ }^{* *} P<0 \cdot 01,{ }^{* * *} P<0.001$ compared with control. (B) In vivo action of L-NAME on islet cNOS activity: islet cNOS activity in islets $2 \mathrm{~min}$ after an i.v. injection of the NOS inhibitor, L-NAME $(1 \cdot 2 \mathrm{mmol} / \mathrm{kg})$ (solid bar) or $0.9 \% \mathrm{NaCl}$ (open bar). NO production was measured as L-citrulline formation $(\mathrm{pmol} / \mathrm{mg}$ protein $/ \mathrm{min})$. Values are means \pm S.E.M. for 4 controls $(0.9 \% \mathrm{NaCl})$ and 5 L-NAMEinjected mice. Two hundred islets were isolated from each of the 9 mice. ${ }^{* *} P<0 \cdot 005$ compared with control. and the pancreas rapidly removed for isolation of the islets. The islets were then thoroughly washed and processed as described in Materials and Methods. Fig. 5B shows that islet cNOS activity in animals injected with L-NAME was suppressed by approximately 55\% compared with saline-injected controls. Hence, the inhibitory action of L-NAME on islet cNOS activity occurred very rapidly as also can be inferred from the rapid effects on insulin release in vitro shown in Fig. 3.

\section{Discussion}

In the present investigation we show for the first time, both in vitro and in vivo, that concentrations of the NOS inhibitor L-NAME, which inhibit islet cNOS activity, also elicit a potentiation of glucose-stimulated insulin release i.e. $\mathrm{NO}$ is apparently a negative modulator of glucose-induced insulin secretion. Moreover, L-NAME was clearly shown to reduce glucagon release in the absence of glucose, thus suggesting that NO is a positive modulator of glucagon release.

\section{Insulin secretion}

Based on previous data from our laboratory we have suggested that low levels of free radicals such as $\mathrm{NO}$ and $\mathrm{H}_{2} \mathrm{O}_{2}$ produced within islet tissue may serve as important physiological modulators of insulin secretory processes (Panagiotidis et al. 1995). With regard to NO, we were the first to propose (Panagiotidis et al. 1992a) that NO derived from islet cNOS activity is a negative modulator of insulin secretion stimulated by arginine. Since then we have repeatedly found, by means of different NOS inhibitors and NO donors applied to isolated islets as well as in experiments performed in vivo, that the main effect of $\mathrm{NO}$ is most likely to suppress insulin release stimulated by glucose or arginine (Åkesson et al. 1996, Salehi et al. 1996, Henningsson \& Lundquist 1998, Salehi et al. 1998b,c, Henningsson et al. 1999). However, as mentioned above, the present data are the first to show that a documented suppression of islet cNOS activity is accompanied by an increase in glucose-stimulated insulin release. In the present study we also found that a marked and significant inhibition of islet cNOS required a rather high concentration of L-NAME $(5 \mathrm{mM})$ when compared with some other tissues previously investigated (Kerwin \& Heller 1994, Knowles \& Moncada 1994) although high concentrations were required for e.g. human platelets and granulocytes (Chen \& Mehta 1996). This may be due to the fact that L-NAME has to be metabolized by an esterase to yield the active NOS inhibitor, $\mathrm{N}^{\mathrm{G}}$-nitro-L-arginine, and reportedly the rate of this reaction may vary between different tissues and cell types (Southan \& Szabó 1996). However, since we previously found that islet cNOS activity was fully inhibited by $50 \mu \mathrm{M}$ L-NAME when the 
drug was added directly to islet homogenates (Salehi et al. 1996) it is also possible that only a certain fraction of the applied NOS inhibitor reached its site of action in the intact islets. Moreover, preliminary data from our laboratory (R Henningsson, A Salehi \& I Lundquist, unpublished data) have shown that another NOS inhibitor, $\mathrm{N}^{\mathrm{G}}$-monomethyl-L-arginine (L-NMMA) in concentrations of 0.5 and $5.0 \mathrm{mM}$ displayed a pattern almost identical to L-NAME in inhibiting islet cNOS and potentiating glucose-induced insulin release in intact, incubated islets. In contrast to our present observations, it was recently reported (Spinas et al. 1998) that $0.5 \mathrm{mM}$ L-NMMA inhibited the first phase of glucose-stimulated insulin release in perifused neonatal rat islets. This finding is probably explained by our recent observation that this low concentration of L-NMMA inhibits glucagon release (Åkesson \& Lundquist 1999), and glucagon is reportedly an initial amplifier of glucose-stimulated insulin release (Schuit \& Pipeleers 1985). Furthermore, it could also be argued that neonatal islets (Spinas et al. 1998) might not be physiologically comparable to freshly isolated adult islets (present study).

In the present investigation we showed that $5 \mathrm{mM}$ L-NAME inhibited cNOS activity in isolated, intact islets by approximately $60 \%$. This concentration of L-NAME might be on the borderline for exerting nonselective effects on insulin secretory mechanisms as judged from our previous experiments showing that $10 \mathrm{mM}$ L-NAME itself (but not $5 \mathrm{mM}$ ) is capable of stimulating insulin release from isolated islets in the presence of a basal, physiological concentration of glucose $(7 \mathrm{mM})$ (Panagiotidis et al. 1995). This is in accordance with recent data (Smith et al. 1997) reporting that $10 \mathrm{mM} \mathrm{L-NAME}$ increases $\left[\mathrm{Ca}^{2+}\right]_{\mathrm{i}}$ in mouse pancreatic $\beta$-cells. Thus it was shown that L-arginine, L-NAME and L-NMMA increased inward $\mathrm{Ca}^{2+}$ currents in patch clamp experiments, whereas L-arginine and L-NMMA generated inward currents leading to depolarization. Furthermore, as mentioned above, it has been proposed that high concentrations of L-NAME $(>5 \mathrm{mM})$ may increase insulin release by directly blocking the $\beta$-cell $\mathrm{K}^{+}{ }_{\text {ATP }}$ channels (Krippeit-Drews et al. 1996). Such a nonspecific effect of L-NAME, however, might be negligible in the present experiments being conducted in the presence of $20 \mathrm{mM}$ glucose, because at this high glucose concentration the $\mathrm{K}^{+}{ }_{\text {ATP }}$ channels were, in all probability, already closed. Moreover, a true NOS inhibitory effect by L-NAME at $20 \mathrm{mM}$ glucose was further verified by our observation that $5 \mathrm{mM}$ L-NAME also exerted a marked potentiating effect on glucose-stimulated insulin release in $\mathrm{K}^{+}$depolarized islets in the presence of $250 \mu \mathrm{M}$ of the $\mathrm{K}^{+}$ATP channel opener, diazoxide. This concentration of diazoxide has previously been found to be sufficient to keep the $\mathrm{K}^{+}{ }_{\text {ATP }}$ channels open in mouse islets (Gembal et al. 1992). This observation also suggests the possibility that the 'glucose augmentation' pathway (Gembal et al. 1992,
Straub et al. 1998) is positively modulated by the L-NAME-induced NOS inhibition. Hence the present data suggest, but do not definitely prove, that the changes in islet NO production following glucose and L-NAME are directly involved in the stimulus-secretion coupling of glucose-induced insulin secretion. However, in strong support of our hypothesis, we have very recently shown (Henningsson et al. 1999) that NO gas, applied to isolated islets, displays a marked inhibitory effect on insulin release stimulated by glucose.

It is of interest to note that $5 \mathrm{mM} \mathrm{L}$-NAME did not influence insulin secretion at basal substimulatory glucose concentrations of 1 and $7 \mathrm{mM}$ glucose (present study) or at $4 \mathrm{mM}$ glucose (Salehi et al. 1996), but greatly enhanced the release at glucose levels $(12-30 \mathrm{mM})$ which stimulate the insulin secretory process. Hence, our observation that the effect of L-NAME on insulin release seemed to increase at insulin stimulating glucose concentrations suggested that glucose itself has the ability to stimulate the production of NO. This assumption was very recently verified in our laboratory by showing that raising the glucose concentration from 7 to $20 \mathrm{mM}$ greatly enhanced islet NOS activity (Henningsson et al. 1999). The present results are also in accordance with our previous data (Salehi et al. 1996) showing that the effect of L-NAME in enhancing insulin release in the presence of a fixed stimulatory concentration of L-arginine $(5 \mathrm{mM})$ was increased with increasing glucose levels. Hence, it is conceivable that a glucose-induced NO production in the $\beta$-cell may, in fact, serve as a brake - i.e. a short negative feedback loop on the insulin secretory mechanisms - in order to prevent an excessive release of insulin at high glucose levels. Such a mechanism is supported by the fact that glucose-stimulated insulin release is accompanied by an increased entry of extracellular $\mathrm{Ca}^{2+}$ into the $\beta$-cell as well as an increased production of NADPH generated from glucose metabolism (Zawalich \& Rasmussen 1990), and that both $\mathrm{Ca}^{2+}$ and NADPH are essential cofactors for stimulating an increase in cNOS activity (Knowles \& Moncada 1994). Our observation that L-NAME could induce a slight increase in insulin release in the total absence of glucose is more difficult to explain, although it is not inconceivable that islet cNOS activity might be increased not only by high glucose but also in the fasted state to prevent unnecessary release of insulin. Furthermore, it cannot be ruled out that a slight effect of L-NAME on the $\mathrm{K}_{\text {ATP }}$ channels could increase insulin release in the absence of glucose, although one would then have expected a similar increase at $1 \mathrm{mM}$ glucose.

As judged from the dynamics of insulin release from perifused islets in the presence of L-NAME, and the finding that islet cNOS activity was already markedly reduced $2 \mathrm{~min}$ after L-NAME injection in vivo, it is evident that the effect of L-NAME in inhibiting islet cNOS activity is rapid in onset. However, the mechanism of action of $\mathrm{NO}$ in inhibiting glucose-induced insulin 
release is still unclear. Since the glucose-stimulated ${ }^{45} \mathrm{Ca}^{2+}$ efflux was modestly increased by the concomitant infusion of L-NAME there is a possibility that NO, derived from glucose stimulation might, in fact, have a slight inhibitory action on the influx of $\mathrm{Ca}^{2+}$. Such an assumption would agree with previous data (Antoine et al. 1996) showing that the intracellular NO donor, hydroxylamine, might have a certain activating effect on the $\mathrm{K}^{+}{ }_{\text {ATP }}$ channels and thus might partially reduce the glucose-induced influx of $\mathrm{Ca}^{2+}$. Inhibition of cNOS by L-NAME might thus counteract an NO-induced activation of the $\mathrm{K}^{+}$ATP channels and instead promote a slight increase in $\mathrm{Ca}^{2+}$ influx and hence an increase in $\left[\mathrm{Ca}^{2+}\right]_{\mathrm{i}}$ which, in turn, might result in a modest further activation of the insulin secretory machinery. Such a mechanism is supported by our recent observation showing that L-NAME could modestly enhance carbachol-induced ${ }^{45} \mathrm{Ca}^{2+}$ efflux in the presence, but not in the absence of extracellular $\mathrm{Ca}^{2+}$ (A kesson \& Lundquist 1998). However, most previous data suggest that an $\mathrm{NO}$-induced inhibition of $\mathrm{Ca}^{2+}$ influx is not the most important signalling mechanism(s) underlying the NOmediated inhibition of glucose-induced insulin release. We have previously proposed (Panagiotidis et al. 1992a, 1994, 1995, Salehi et al. 1996) that the inhibitory action of $\mathrm{NO}$ on nutrient-induced insulin release might be exerted through the formation of S-nitrosothiols (Stamler et al. 1992), thereby impairing thiol groups essential for the nutrient-induced insulin secretory process (Hellman et al. 1974, Ammon \& Mark 1985). Moreover, since we have shown here that the potentiating effect of L-NAME on glucose-induced insulin release seems to be exerted mainly independently of membrane depolarization events and in the presence of the $\mathrm{K}_{\text {ATP }}^{+}$channel opener, diazoxide, it seems very likely that the major effect of $\mathrm{NO}$ is exerted at distal events in the stimulus-secretion coupling i.e. in processes close to or even directly implicated in exocytosis. The precise nature of which thioldependent regulatory proteins in the signalling events are targeted by $\mathrm{NO}$, however, remains to be elucidated.

The accumulated data from our in vitro experiments strongly suggested that $\mathrm{NO}$ is a negative modulator of glucose-induced insulin release. Such an effect should, however, preferably be shown also in vivo. In order to avoid, as far as possible, any indirect systemic effects of L-NAME in the in vivo situation, we injected the drug i.v. 15 s prior to a rapid i.v. injection of glucose. In accordance with the in vitro perifusion experiments the immediate in vivo effect of L-NAME to suppress islet cNOS was reflected in a marked potentiation of the glucose-induced insulin response 2 min after injection of the sugar and also in a marked improvement of the glucose tolerance curve. Hence, our complementary in vivo data supported our in vitro results and suggested that L-NAME rapidly reached its target and site of action, the cNOS enzyme, in the $\beta$-cell interior. It should be noted, in view of the known vascular effects of NO, that L-NAME might be supposed to have changed the insulin response to glucose by modifying pancreatic blood-flow. However, this seems very unlikely, because the insulin response was enhanced at the same time as the glucagon response was suppressed. Furthermore, previous studies (Jansson \& Sandler 1991, Gross et al. 1995) did not reveal any specific effects of NOS inhibition on islet blood flow in the isolated perfused pancreas.

\section{Glucagon secretion}

In a series of previous communications (Panagiotidis et al. 1994, Åkesson et al. 1996, Salehi et al. 1996, 1998b,c, Åkesson \& Lundquist 1998, 1999, Henningsson \& Lundquist 1998, Henningsson et al. 1999) we have presented evidence that $\mathrm{NO}$ is a positive modulator of glucagon secretion, showing that glucagon release stimulated by L-arginine or the cholinergic agonist carbachol is always inhibited by L-NAME both in vitro and in vivo. The present results support such a notion. Thus, in the absence of glucose when the rate of glucagon release is high (cf. Fig. 2) the NOS inhibitor L-NAME clearly suppressed glucagon release. However, in the presence of different concentrations of glucose this effect of L-NAME was masked, most likely explained by the fact that glucose itself, as well as insulin are known as powerful inhibitors of glucagon release. Similarly, our present observation that L-NAME-induced inhibition of islet cNOS activity in the in vivo experiments brought about a significantly more pronounced suppression of the plasma glucagon levels as compared with the controls at 20 and 40 min following the i.v. injection of glucose is most probably due to the markedly enhanced insulin release at 2 and $6 \mathrm{~min}$.

\section{Conclusion}

In the present investigation we have shown, for the first time, that a biochemically verified suppression of islet cNOS activity induced by the NOS-inhibitor L-NAME is accompanied by a marked increase in glucose-stimulated insulin release both in vitro and in vivo. The NOSinhibitory action is rapid in onset and results in an immediate increase in glucose-induced insulin release. Furthermore, inhibition of islet cNOS seems to have little influence on islet $\mathrm{Ca}^{2+}$ fluxes. The major action of $\mathrm{NO}$ to inhibit glucose-induced insulin release is apparently exerted independently of membrane depolarization events and is presumably focussed at a more distal site in the stimulus-secretion coupling. Finally, glucagon release in a glucose-free medium is inhibited by NOS inhibition. Hence, the accumulated evidence supports our previous hypothesis that NO is a negative modulator of glucosestimulated insulin release but has a stimulatory effect on glucagon release. 


\section{Acknowledgements}

This study was supported by the Swedish Medical Research Council (14X-4286), the Swedish Diabetes Association, the Swedish Society of Medical Research, the Albert Påhlsson Foundation and the Ake Wiberg Foundation. The technical assistance of Britt-Marie Nilsson and the secretarial help of Eva Björkbom are gratefully acknowledged.

\section{References}

Ahrén B \& Lundquist I 1982 Glucagon immunoreactivity in plasma from normal and dystrophic mice. Diabetologia 22 258-263.

Åkesson B \& Lundquist I 1996 Modulation of the islet nitric oxide system and sulphonylurea-induced insulin secretion. Diabetes Research 31 91-99.

Åkesson B \& Lundquist I 1998 Evidence for nitric oxide mediated effects on islet hormone secretory phospholipase C signal transduction mechanisms. Bioscience Reports 18 199-213.

Åkesson B \& Lundquist I 1999 Influence of nitric oxide modulators on cholinergically stimulated hormone release from mouse islets. Journal of Physiology 515 463-473.

Åkesson B, Mosén H, Panagiotidis G \& Lundquist I 1996 Interaction of the islet nitric oxide system with L-arginine-induced secretion of insulin and glucagon in mice. British Journal of Pharmacology 119 758-764.

Ammon HPT \& Mark M 1985 Thiols and pancreatic $\beta$-cell function: a review. Cell Biochemistry and Function 3 157-171.

Antoine M-H, Oudraogo R, Sergooris J, Hermann M, Herchuelz A \& Lebrun P 1996 Hydroxylamine, a nitric oxide donor, inhibits insulin release and activates $\mathrm{K}^{+}{ }_{\text {АтP }}$ channels. European Journal of Pharmacology 313 229-235.

Bradford MM 1978 A rapid and sensitive method for the quantitation of microgram quantities of protein utilizing the principle of protein-dye binding. Analytical Biochemistry 84 309-312.

Bredt DS \& Snyder SH 1989 Nitric oxide mediates glutamate-linked enhancement of cGMP levels in cerebellum. Proceedings of the National Academy of Sciences of the USA 86 9030-9033.

Bruss ML \& Black AL 1978 Enzymatic microdetermination of glycogen. Analytical Biochemistry 84 309-312.

Carlberg M 1994 Assay of neuronal nitric oxide synthase by HPLC determination of citrulline. Journal of Neuroscience Methods $\mathbf{5 2}$ 165-167.

Chen LY \& Mehta JL 1996 Variable effects of L-arginine analogs on L-arginine-nitric oxide pathway in human neutrophils and platelets may relate to different nitric oxide synthase isoforms. Journal of Pharmacology and Experimental Therapeutics 276 253-257.

Corbett JA, Wang JL, Misko TP, Zhao W, Hickey WF \& McDaniel ML 1993 Nitric oxide mediates IL-1 $\beta$-induced islet dysfunction and destruction: prevention by dexamethasone. Autoimmunity 15 145-153.

Cunningham JM, Mabley JG, Delaney CA \& Green IC 1994 The effect of nitric oxide donors on insulin secretion, cyclic GMP and cyclic AMP in rat islets of Langerhans and the insulin-secreting cell lines HIT-T15 and RINm5F. Molecular and Cellular Endocrinology $10223-29$.

Gembal M, Gilon P \& Henquin JC 1992 Evidence that glucose can control insulin release independently from its action on ATP-sensitive $\mathrm{K}^{+}$channels in mouse B cells. Journal of Clinical Investigation 89 1288-1295.

Gotoh M, Maki T, Kiyoizumi T, Satomi S \& Monaco AP 1985 An improved method for isolation of mouse pancreatic islets. Transplantation $\mathbf{4 0}$ 437-438.
Gross R, Roye M, Manteghetti M, Hillaire-Buys D \& Ribes G 1995 Alterations of insulin response to different $\beta$ cell secretagogues and pancreatic vascular resistance induced by $\mathrm{N}^{\omega}$-nitro-L-arginine methyl ester. British Journal of Pharmacology 116 1965-1972.

Heding L 1966 A simplified insulin radioimmunoassay method. In Labelled Proteins in Tracer Studies, pp 345-350. Eds L Donato, G Milhaud \& J Sirchis. Brussels: Euratom.

Hellman B, Idahl L- ̊, Lernmark ̊̊, Sehlin J \& Täljedal I-B 1974 Membrane sulfhydryl groups and pancreatic beta cell recognition of insulin secretagogues. Excerpta Medica International Congress Series $31265-78$.

Henningsson R \& Lundquist I 1998 Arginine-induced insulin release is decreased and glucagon increased in parallel with islet NO production. American Journal of Physiology 275 E500-E506.

Henningsson R, Alm P, Ekström P \& Lundquist I 1999 Heme oxygenase and carbon monoxide: regulatory roles in islet hormone release. A biochemical, immunohistochemical, and confocal microscopic study. Diabetes 48 66-76.

Jansson L \& Sandler S 1991 The nitric oxide synthase inhibitor II $\mathrm{N}^{\mathrm{G}}$-nitro L-arginine stimulates pancreatic islet insulin release in vitro, but not in the perfused pancreas. Endocrinology 128 3081-3085.

Jones PM, Persaud SJ, Bjaaland T, Pearson JD \& Howell SL 1992 Nitric oxide is not involved in the initiation of insulin secretion from rat islets of Langerhans. Diabetologia 35 1020-1027.

Kerwin JF \& Heller M 1994 The arginine-nitric oxide pathway: A target for new drugs. Medicinal Research Reviews 14 23-27.

Knowles RG \& Moncada S 1994 Nitric oxide synthases in mammals. Biochemical Journal 298 249-258.

Krippeit-Drews P, Welker S \& Drews G 1996 Effects of the nitric oxide synthase inhibitor $\mathrm{N}^{\omega}$-nitro-L-arginine methyl ester on electrical activity and ion channels of mouse pancreatic B cells. Biochemical and Biophysical Research Communications 224 199-205.

Laffranchi R, Gogvadze V, Richter C \& Spinas GA 1995 Nitric oxide (nitrogen monoxide, NO) stimulates insulin secretion by inducing calcium release from mitochondria. Biochemical and Biophysical Research Communications 217 584-591.

Laychock RG, Modica ME \& Cavanaugh CT 1991 L-Arginine stimulates cyclic guanosine $3^{\prime}, 5^{\prime}$-monophosphate formation in rat islets of Langerhans and RINm5F insulinoma cells: evidence for L-arginine:nitric oxide synthase. Endocrinology 129 3043-3052.

Moncada S, Palmer RMJ \& Higgs EA 1991 Nitric oxide: physiology, pathophysiology, and pharmacology. Pharmacological Reviews $\mathbf{4 3}$ 109-142.

Panagiotidis G, Alm P \& Lundquist I 1992a Inhibition of islet nitric oxide synthase increases arginine-induced insulin release. European Journal of Pharmacology 229 277-278.

Panagiotidis G, Salehi AA, Westermark P \& Lundquist I $1992 b$ Homologous islet amyloid polypeptide: effects on plasma levels of glucagon, insulin and glucose in the mouse. Diabetes Research and Clinical Practice 18 167-171.

Panagiotidis G, Åkesson B, Alm P \& Lundquist I 1994 The nitric oxide system in the endocrine pancreas induces differential effects on the secretion of insulin and glucagon. Endocrine 2 787-792.

Panagiotidis G, Åkesson B, Rydell EL \& Lundquist I 1995 Influence of nitric oxide synthase inhibition, nitric oxide and hydroperoxide on insulin release induced by various secretagogues. British Journal of Pharmacology 114 289-296.

Rerup C \& Lundquist I 1966 Blood glucose level in mice. Evaluation of a new technique of multiple serial sampling. Acta Endocrinologica 52 357-367.

Salehi A, Carlberg M, Henningsson R \& Lundquist I 1996 Islet constitutive nitric oxide synthase: biochemical determination and regulatory function. American Journal of Physiology 270 C1634-C1641.

Salehi A, Mosén H \& Lundquist I 1998a Insulin release transduction mechanism through acid glucan 1,4- $\alpha$-glucosidase activation is $\mathrm{Ca}^{2+}$ regulated. American Journal of Physiology 274 E459-E468. 
Salehi A, Parandeh F \& Lundquist I 1998b Signal transduction in islet hormone release: interaction of nitric oxide with basal and nutrient-induced hormone responses. Cellular Signalling 10 645-651.

Salehi A, Parandeh F \& Lundquist I 1998c The nitric oxide synthase inhibitor $\mathrm{N}^{\mathrm{G}}$-nitro-L-arginine methyl ester potentiates insulin secretion stimulated by glucose and L-arginine independently of its action on ATP-sensitive $\mathrm{K}^{+}$channels. Bioscience Reports 18 19-28.

Schmidt HHHW, Warner TD, Ishii K, Sheng H \& Murad F 1992 Insulin secretion from pancreatic B cells caused by L-arginine-derived nitrogen oxides. Science 255 721-723.

Schuit FC \& Pipeleers DG 1985 Regulation of adenosine 3',5'monophosphate levels in the pancreatic B cell. Endocrinology 117 834-840.

Sjöholm A 1996 Nitric oxide donor SIN-1 inhibits insulin release. American Journal of Physiology 271 C1098-C1102.

Smith PA, Sakura H, Coles B, Gummerson N, Proks P \& Ashcroft FA 1997 Electrogenic arginine transport mediates stimulus-secretion coupling in mouse pancreatic $\beta$-cells. Journal of Physiology 499 625-635.

Southan GJ \& Szabó C 1996 Selective pharmacological inhibition of distinct nitric oxide synthase isoforms. Biochemical Pharmacology 51 383-394.
Spinas GA, Laffranchi R, Francoys I, David I, Richter C \& Reinecke M 1998 The early phase of glucose-stimulated insulin secretion requires nitric oxide. Diabetologia 41 292-299.

Stamler JS, Simon DI, Osborne JA, Mullins ME, Jaraki O, Michel T, Singel DJ \& Loscalzo J 1992 S-nitrosylation of proteins with nitric oxide, synthesis and characterization of biologically active compounds. Proceedings of the National Academy of Sciences of the USA 89 444-448.

Straub SG, James RF, Dunne MJ \& Sharp GW 1998 Glucose activates both K(ATP) channel-dependent and K(ATP) channel-independent signaling pathways in human islets. Diabetes 47 758-763.

Willmott NJ, Galione A \& Smith PA 1995 Nitric oxide induces intracellular $\mathrm{Ca}^{2+}$ mobilization and increases secretion of incorporated 5 -hydroxytryptamine in rat pancreatic $\beta$-cells. FEBS Letters 371 99-104.

Zawalich WS \& Rasmussen H 1990 Control of insulin secretion: a model involving $\mathrm{Ca}^{2+}$, cAMP and diacylglycerol. Molecular and Cellular Endocrinology 70 119-137.

Received 16 February 1999

Accepted 27 May 1999 